\title{
Indicadores educacionais na avaliação da educação básica e possiveis impactos em escolas de Ensino Médio no município de Porto Alegre, Rio Grande do Sul
}

\author{
Ricardo Ferreira Vitelli' (D) \\ Rosangela Fritsch' (D) \\ Berenice Corsettil (ID
}

RESUMO

O texto descreve indicadores de avaliação de contexto desenvolvidos pelo Instituto Nacional de Estudos e Pesquisas Educacionais Anísio Teixeira e sua aplicação em escolas públicas de ensino médio, para identificar possíveis implicações com indicadores de fluxo escolar. Utilizou-se a base de dados do referido instituto, submetida a tratamento estatístico por meio da análise de regressão múltipla. Ao identificar a relação existente entre os indicadores analisados, percebeu-se a necessidade de se relativizar o uso de resultados de indicadores educacionais na avaliação da qualidade da educação.

PALAVRAS-CHAVE

indicadores educacionais; escolas públicas; ensino médio.

'Universidade do Vale do Rio dos Sinos, São Leopoldo, RS, Brasil. 
EDUCATIONAL INDICATORS IN BASIC EDUCATION

ASSESSMENT AND POSSIBLE IMPACTS IN

SECONDARY EDUCATION SCHOOLS IN THE CITY OF

PORTO ALEGRE, STATE OF RIO GRANDE DO SUL

\begin{abstract}
This text described the context indicated the context indicators analyzed in order to identify the processes with school flow indicators. It was based on Instituto Nacional de Estudos e Pesquisas Educacionais Anísio Teixeira data, for statistical treatment through a multiple regression analysis. When identifying the relation between indicators, it was noticed that there is a need to relativize or use the results of educational indicator in the evaluation of education quality.
\end{abstract}

KEYWORDS

educational indicators; public schools; high school.

INDICADORES EDUCATIVOS EN LA EVALUACIÓN

DE LA EDUCACIÓN BÁSICA Y POSIBLES IMPACTOS

EN ESCUELAS SECUNDÁRIAS DEL MUNICÍPIO

DE PORTO ALEGRE, RIO GRANDE DO SUL

\title{
RESUMEN
}

Este artículo describe los indicadores de contexto en análisis para identificar los procesos com indicadores de flujo escolar. Se ha utilizado la base de datos del Instituto Nacional de Estudos e Pesquisas Educacionais Anísio Teixeira, sometida a un tratamiento estadístico por medio del análisis de regresión múltiple. Al identificar la relación entre los indicadores, se ha percibido la necesidad de relativizar o utilizar los resultados de los indicadores educativos en la evaluación de la calidad de educación.

PALABRAS CLAVE

indicadores educativos; escuelas públicas; educación secundaria. 


\section{INTRODUÇÃO}

A constituição e a consolidação do Sistema de Avaliação da Educação Básica (SAEB) vêm tendo centralidade no cenário educacional brasileiro a partir da década de 1980 com políticas pautadas na avaliação em larga escala e em indicadores educacionais (Bonamino, 2002; Freitas, 2007; Silva e Cunha, 2014; Souza, Duarte e Oliveira, 2015; Werle, 2012). Nesse contexto, são perceptíveis os movimentos recentes de incorporação de indicadores educacionais de avaliação de contexto da educação básica que se fazem presentes desde 2014, quando o Instituto Nacional de Estudos e Pesquisas Educacionais Anísio Teixeira (INEP) disponibilizou um conjunto de indicadores em seu site.

O INEP, a partir de agosto de 2015, tornou pública a plataforma Painel Educacional, disponibilizando informações definidas como de trajetória (matrículas, média de estudantes por turma, estudantes incluídos, matrículas em tempo integral, taxa de aprovação, taxa de reprovação, taxa de abandono e taxa de distorção idade-série), de aprendizagem (participação de estudantes e escolas nas avaliações e resultados) e de contexto (indicador de nível socioeconômico, indicador de complexidade da gestão escolar, indicador de esforço docente, indicador de adequação da formação docente, indicador de regularidade docente e indicador de desenvolvimento da educação básica). Tendo isso em vista, este artigo apresenta e descreve esses indicadores de avaliação de contexto, ampliando o seu conhecimento, na medida em que passam a integrar o sistema de avaliação, conforme evidenciado na instituição do Sistema Nacional de Avaliação da Educação Básica (SINAEB). ${ }^{1}$ Além desse objetivo central, este estudo aplica tais indicadores no contexto de escolas públicas de ensino médio localizadas em Porto Alegre, Rio Grande do Sul, buscando compreender suas implicações nos seguintes indicadores de trajetória de fluxo escolar: aprovação, reprovação, defasagem idade-série e abandono escolar.

Algumas premissas orientam este artigo. Uma delas considera que o conceito de qualidade da educação precisa ser adjetivado, pois sua definição carrega um ideário marcado pela supervalorização de políticas de avaliação, como a que acontece em larga escala, e consequentemente pela sofisticação de tecnologias e metodologias quantitativas de medição da eficácia e da eficiência por meio de indicadores educacionais. $\mathrm{O}$ conceito de qualidade da educação apresenta um caráter polissêmico, podendo ser empregado com diferentes significados. Desde a implantação das políticas de avaliação em larga escala, a qualidade da educação passou a ser identificada como o resultado da adoção de indicadores educacionais obtidos por meio de testes e de sua combinação com outros índices. No entendimento dos autores

1 Em 5 de maio de 2016, a portaria n. 369 do Ministério da Educação (MEC) instituiu o Sistema Nacional de Avaliação da Educação Básica (SINAEB), em substituição ao SAEB (Brasil, 2016). Em 25 de agosto de 2016, por meio da portaria n. 981, o MEC reviu essa decisão ao revogar a portaria anterior, com o argumento de que havia um sistema nacional para esse fim consolidado e qualquer revisão seria inoportuna enquanto não se concretizar a revisão da Base Nacional Comum Curricular (BNCC). 
deste texto, a qualidade da educação não pode ser expressa apenas por indicadores quantitativos, necessitando, para ampliação de sua abrangência, da incorporação de elementos qualitativos e também de outros indicadores que possam retratar mais adequadamente a realidade escolar.

A educação, na perspectiva de negócio e de práticas de gestão gerencialistas, é regulada por um Estado avaliador que protagoniza e focaliza a medição e os resultados evidenciados comumente como indicadores educacionais de desempenho (números, taxas e índices), proliferando e instituindo as avaliações em larga escala e os rankings. Nesse contexto, para um Estado avaliador, a perfomatividade é um aspecto-chave e configura-se como tecnologia de gestão de desempenho.

De fato, a performatividade é a forma por excelência de governamentabilidade neoliberal, que abrange a subjetividade, as práticas institucionais, a economia $\mathrm{e}$ o governo. É tanto individualizante, quanto totalizante. Ela produz docilidade ativa e produtividade sem profundidade. A performatividade convida-nos e incita-nos a tornarmo-nos mais efetivos, a trabalharmos em relação a nós mesmos e a sentirmo-nos culpados ou inadequados se não o fizermos. Ela opera dentro de um arcabouço de julgamento no qual a definição de "aperfeiçoamento" e de eficácia é determinada por nós e "indicada” por medidas de qualidade e de produtividade. (Ball, 2014, p. 66)

A performatividade é operada, assim, por meio de metas que instigam a comparação entre indicadores de diferentes instituições e sistemas. Dessa forma, a proliferação de indicadores educacionais contribui para, como afirma Ball (2014), produzir docilidade ativa e produtividade sem profundidade.

Entendemos os indicadores como metodologias de medição, que têm o objetivo predeterminado de retratar, de alguma forma, a realidade pesquisada, porém, em virtude de suas limitações, não avaliam de fato a qualidade da educação. Consistem, na verdade, em sinais e recursos metodológicos, que podem ser qualitativos ou quantitativos e expressam, a partir de um significado particular, um resultado, uma característica ou o desempenho de uma ação, de um processo ou de um serviço, podendo positivamente assumir uma função diagnóstica de amplitude social e subsidiar a formulação de políticas públicas (Jannuzzi, 2002, 2009).

Ressalta-se, assim, que o uso de indicadores como instrumento de gestão tem relevância tanto no planejamento quanto no monitoramento de práticas desenvolvidas para a melhoria da qualidade de uma ação, de um serviço, de um produto ou de uma política. Contudo, são insuficientes e limitados quando assumidos para propósitos como o de avaliar a qualidade da educação.

Diante disso, para atingir os objetivos propostos, o presente texto, além desta introdução e das considerações finais, está organizado em duas seções. Na primeira, apresenta-se e descreve-se o conjunto de indicadores de avaliação institucional. $\mathrm{Na}$ segunda, discorre-se acerca da aplicação dos indicadores relacionados com o fluxo desempenho em escolas estaduais de ensino médio situadas no município de Porto Alegre. 


\section{INDICADORES DE AVALIAÇÃO DE CONTEXTO}

No Quadro 1 são apresentados cinco indicadores de avaliação de contexto, no qual podem ser visualizados o nome do indicador, sua representação simplificada e seu objetivo, conforme documentos (notas técnicas) disponibilizados no site do INEP, no campo informações estatísticas/indicadores educacionais.

$\mathrm{O}$ indicador de adequação da formação docente, conforme nota técnica n. 20/2014 do MEC/INEP, avalia a adequação da formação inicial dos docentes das escolas brasileiras de educação básica segundo orientações legais e utiliza, para a coleta de dados, o Censo Escolar da Educação Básica, extraindo informações sobre a formação de docentes, as turmas em que atuam e as disciplinas que lecionam, além de dados sobre os alunos e as escolas (Brasil, 2014a). Até agosto de 2015, data da coleta de dados deste artigo, foram analisados pelo INEP os elementos referentes ao ano de 2013. A constituição desse indicador pelo referido instituto ocorreu valendo-se de fundamentação legal, ou seja, da análise dos atos normativos sobre o tema que envolve o indicador. A análise realizada começa com o artigo 62 da Lei de Diretrizes e Bases da Educação Nacional (LDBEN) de 1996, que prevê:

A formação de docentes para atuar na educação básica far-se-á em nível superior, em curso de licenciatura, de graduação plena, em universidades e institutos superiores de educação, admitida, como formação mínima para o exercício do magistério na educação infantil e nos 5 (cinco) primeiros anos do ensino fundamental, a oferecida em nível médio na modalidade normal. (Brasil, 1996)

Quadro 1 - Indicadores de avaliação de contexto.

\begin{tabular}{|l|c|c|}
\hline $\begin{array}{l}\text { Nome do } \\
\text { indicador }\end{array}$ & $\begin{array}{c}\text { Representação } \\
\text { do indicador }\end{array}$ & Objetivos do indicador \\
\hline $\begin{array}{l}\text { Adequação da } \\
\text { formação docente }\end{array}$ & AFD & $\begin{array}{c}\text { Avaliar a adequação da formação inicial dos docentes } \\
\text { das escolas de educação básica brasileira, segundo as } \\
\text { orientações legais. }\end{array}$ \\
\hline $\begin{array}{l}\text { Regularidade do } \\
\text { corpo docente }\end{array}$ & IRD & $\begin{array}{l}\text { Avaliar a regularidade do corpo docente nas escolas de } \\
\text { educação básica com base na observação da permanência dos } \\
\text { professores nas escolas nos últimos cinco anos (2009 a 2013). }\end{array}$ \\
\hline Esforço docente & IED & $\begin{array}{l}\text { Medir o esforço empreendido pelos docentes da educação } \\
\text { básica brasileira no exercício de sua profissão. }\end{array}$ \\
\hline $\begin{array}{l}\text { Complexidade de } \\
\text { gestão da escola }\end{array}$ & ICG & $\begin{array}{l}\text { Mensurar o nível de complexidade de gestão das escolas } \\
\text { brasileiras de educação básica. }\end{array}$ \\
\hline $\begin{array}{l}\text { Nível } \\
\text { socioeconômico }\end{array}$ & INSE & $\begin{array}{l}\text { Situar o conjunto dos alunos atendidos por cada escola em } \\
\text { um estrato, definido pela posse de bens domésticos, pela } \\
\text { renda e pela contratação de serviços por parte da família } \\
\text { dos alunos e pelo nível de escolaridade dos pais. }\end{array}$ \\
\hline
\end{tabular}

Fonte: Brasil (2004).

Elaboração dos autores. 
Em seguida, para a constituição desse indicador, o INEP analisou o parecer n. 02/2008 do Conselho Nacional de Educação (CNE), que agrupa as diferentes formações para a atuação docente na educação básica em duas trajetórias: a formação multidisciplinar (educação infantil e anos iniciais do ensino fundamental), que pode ser conquistada nos cursos de pedagogia, compreendidos como licenciatura plena, normal superior ou em cursos de pós-graduação específicos; e a formação em campos específicos, que deve acontecer por meio dos diversos cursos de licenciatura plena para o ensino de sua especialidade.

O que o indicador avalia são as docências oferecidas pela escola e por seu corpo professoral. Para cada uma das disciplinas analisadas, foi identificada a formação do docente responsável por seu desenvolvimento na turma, com base nos dados do Censo Escolar. A fundamentação legal orientou a análise dos dados e possibilitou a identificação de cinco perfis de regência das disciplinas, conforme apresentado no Quadro 2.

Considerando apenas o Grupo 1, que corresponde à melhor situação possível, a distribuição dos docentes no ensino médio do Brasil é apresentada na Figura 1.

\section{Quadro 2 - Categorias de formação da adequação do docente em relação à disciplina que leciona.}

\begin{tabular}{|l|c|}
\hline Grupo & Descrição \\
\hline 1 & $\begin{array}{r}\text { Docentes com formação superior em licenciatura na mesma disciplina que lecionam ou em } \\
\text { bacharelado com curso de complementação pedagógica concluído. }\end{array}$ \\
\hline 2 & $\begin{array}{r}\text { Docentes com formação superior em bacharelado na disciplina correspondente, mas sem } \\
\text { licenciatura ou complementação pedagógica. }\end{array}$ \\
\hline 3 & $\begin{array}{c}\text { Docentes com licenciatura em área diferente daquela que lecionam ou com bacharelado } \\
\text { nas disciplinas da base curricular comum e complementação pedagógica concluída em área } \\
\text { diferente daquela que lecionam. }\end{array}$ \\
\hline 5 & Docentes com outra formação superior não considerada nas categorias anteriores. \\
\hline 5 & Docentes que não possuem curso superior completo. \\
\hline
\end{tabular}

Fonte: Brasil (2014a).

Elaboração dos autores.

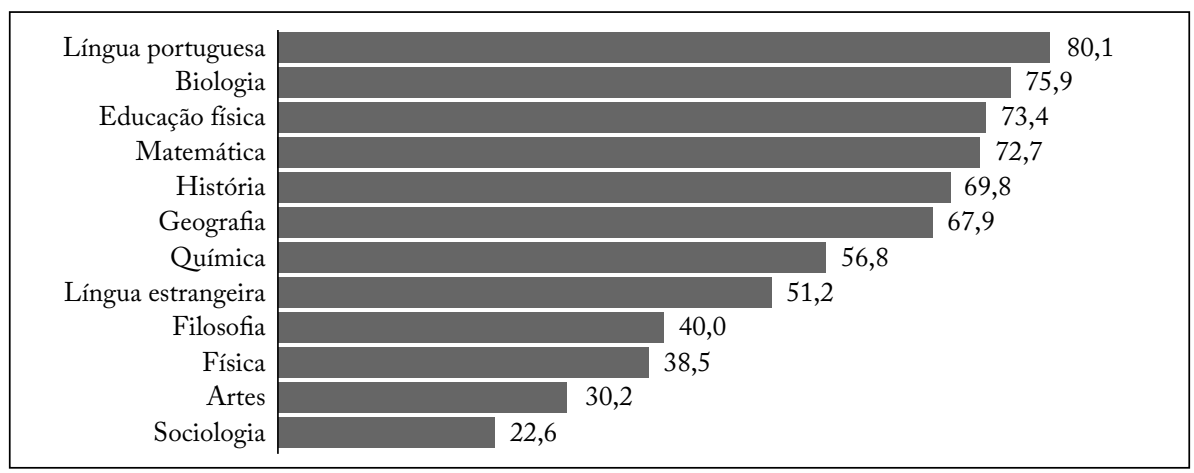

Figura 1 - Distribuição percentual dos docentes das disciplinas da grade curricular comum do ensino médio enquadrados na categoria Grupo 1, do indicador de adequação docente em relação à disciplina que leciona - Brasil, 2013. 
Pode-se perceber que a maior prevalência de docentes no Grupo 1 ocorre nas áreas de língua portuguesa, biologia, educação física e matemática, que alcançam um número acima de $70 \%$ do corpo de docentes nessas condições. Os profissionais das demais áreas têm uma incidência das características do Grupo 1, no entanto apresentando valor abaixo de $70 \%$. Destaca-se a situação dos docentes de filosofia, física, artes e sociologia, que alcançam índices de no máximo 40\%, situação que merece um estudo mais circunstanciado acerca de tal fenômeno.

$\mathrm{O}$ indicador de regularidade docente foi constituído, conforme nota técnica n. 11/2015, com a finalidade de avaliar a regularidade do corpo docente nas escolas de educação básica, valendo-se da observação da permanência dos professores nas escolas nos últimos cinco anos (2009 a 2013). Foram consideradas, nessa análise, as escolas em atividade nos anos de 2009 a 2013, além de todos os docentes informados no Censo Escolar em pelo menos um dos cinco anos analisados (Brasil, 2015).

Observando os dados analisados pelo INEP referentes ao ano de 2013, pode-se notar que o indicador de regularidade do corpo docente atribui uma pontuação de modo que a presença em anos mais recentes seja mais valorizada e a regularidade em anos consecutivos também seja considerada. Dessa maneira, conforme Tabela 1, é possível verificar que a pontuação é maior para os períodos mais recentes, caso do ano de 2013 (60 pontos), por exemplo.

Considerando apenas a pontuação por presença (PP), para o professor presente na escola em 2013, o escore é de 60 pontos; para 2012, 30 pontos; 2011, 20 pontos; 2010,15 pontos;2009, 12 pontos. Entretanto, para o docente que permanece na mesma escola por dois anos consecutivos, a pontuação atribuída ao ano mais antigo é acrescida da pontuação por regularidade (PR). Dessa forma, se um docente estava presente na escola em 2012 e 2013, ele receberia em 2012 a pontuação de 45 (30 pontos relativos à $\mathrm{PP}$ e 15 pontos relativos à $\mathrm{PR}$ ) e em 2013 a pontuação de 60 (pontos relativos à $\mathrm{PP}$ ). O mesmo cálculo é feito para outros eventuais pares de anos consecutivos.

$\mathrm{O}$ indicador de regularidade docente é definido como a pontuação final de cada par professor-escola $\left(\mathrm{PF}_{\mathrm{ij}}\right)$, padronizada para variar de zero a cinco. Como a maior pontuação possível é de 161 pontos, o indicador padronizado para uma escala de zero a cinco é obtido dividindo-se a pontuação final por 161 e multiplicando-se o resultado por cinco, como pode ser observado na Equação 1.

Tabela 1 - Pontuação por presença e regularidade do docente na escola, por ano de atuação.

\begin{tabular}{l|c|c}
\hline Ano & Pontuação por presença & Pontuação por regularidade $^{* *}$ \\
\hline 2013 & 60 & - \\
\hline 2012 & 30 & 15,0 \\
\hline 2011 & 20 & 5,0 \\
\hline 2010 & 15 & 2,5 \\
\hline 2009 & 12 & 1,5 \\
\hline
\end{tabular}

*A pontuação por presença (PP) em cada ano é condicionada à atuação do professor na escola no mesmo ano; **A pontuação por regularidade (PR) em cada ano é condicionada à atuação do professor na escola no mesmo ano e no ano seguinte. Fonte: Brasil (2015).

Elaboração dos autores. 
EQUAÇÃO 1 - ÍNDICE DE REGULARIDADE DOCENTE

$I R D_{i j}=5 x \frac{P F_{i j}}{161}$

Onde:

$\mathrm{IRD}_{\mathrm{ij}}=$ indicador de regularidade do corpo docente; $\mathrm{PF}_{\mathrm{ij}}=$ pontuação final (professor i em uma escola $\mathrm{j}$ ).

Fonte: Brasil (2015).

Assim, quanto mais próximo de zero, mais irregular é o docente; e, quanto mais próximo de cinco, mais regular ele é - esse é o mesmo tipo de relação que o cálculo do indicador da escola representa. A Tabela 1 mostra o(s) ano(s) em que o docente esteve na escola e sua respectiva PP, e, caso continue na escola em anos seguintes, é acrescida mais uma pontuação, descrita como PR. A intenção dessa pontuação é valorizar mais os docentes que se mantêm na mesma escola em anos subsequentes.

Nas Figuras 2 e 3, são apresentadas as distribuições percentuais das funções docentes, segundo o indicador de regularidade do corpo docente, e das escolas de educação básica, de acordo com a média ponderada desse mesmo indicador. A distribuição das funções docentes no Brasil (Figura 2) indica que 63\% destas ficam concentradas na posição de baixa regularidade, ou seja, apresentam docentes que têm pouca regularidade nas escolas. Esse resultado reflete a ideia de que os professores tendem a não permanecer muito tempo na mesma escola.

Se se lançar o olhar sobre a situação das escolas, pode-se perceber que a concentração se desloca para as faixas medianas de regularidade docente, conforme é possível visualizar na Figura 3.

O indicador de esforço docente é apresentado na nota técnica n. 39/2014 e mensura o esforço empreendido pelos docentes da educação básica brasileira no exercício de sua profissão (Brasil, 2014b). Foram consideradas na análise desse indicador as seguintes características acerca da atuação docente, retiradas do Censo

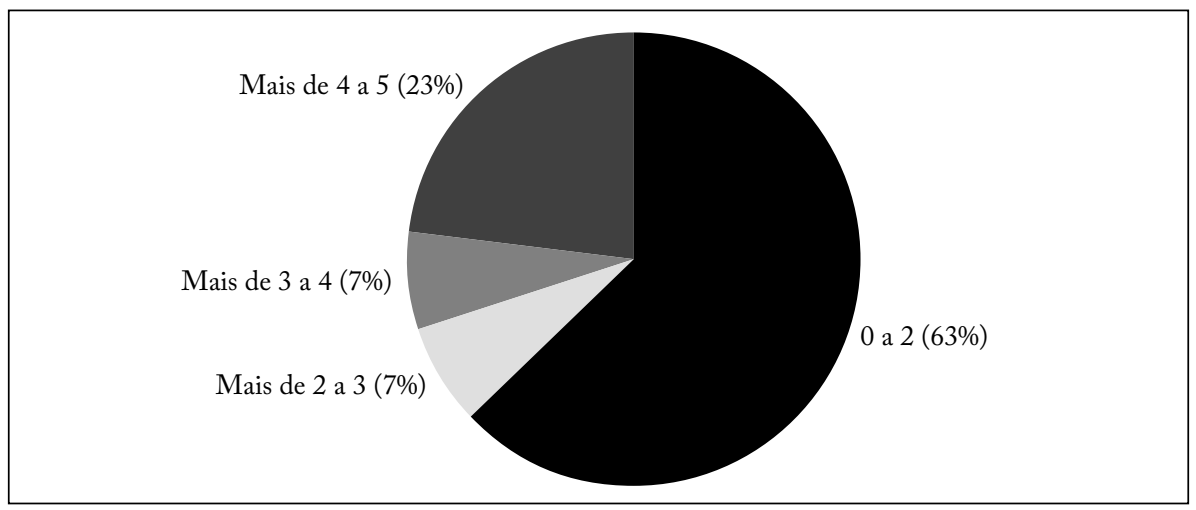

Figura 2 - Pontuação por presença e regularidade do docente na escola por ano de atuação - Brasil, 2013.

Fonte: Brasil (2015).

Elaboração dos autores. 
da Educação Básica de 2013: número de escolas em que trabalha; número de turnos em exercício; número de alunos atendidos; e número de etapas nas quais leciona. As variáveis criadas para representar tais atributos são do tipo ordinal, de modo que as categorias mais elevadas indicam maior esforço por parte do professor (Quadro 3). Tomando como base essas características, é possível posicionar o docente em uma escala de esforço despendido na atividade.

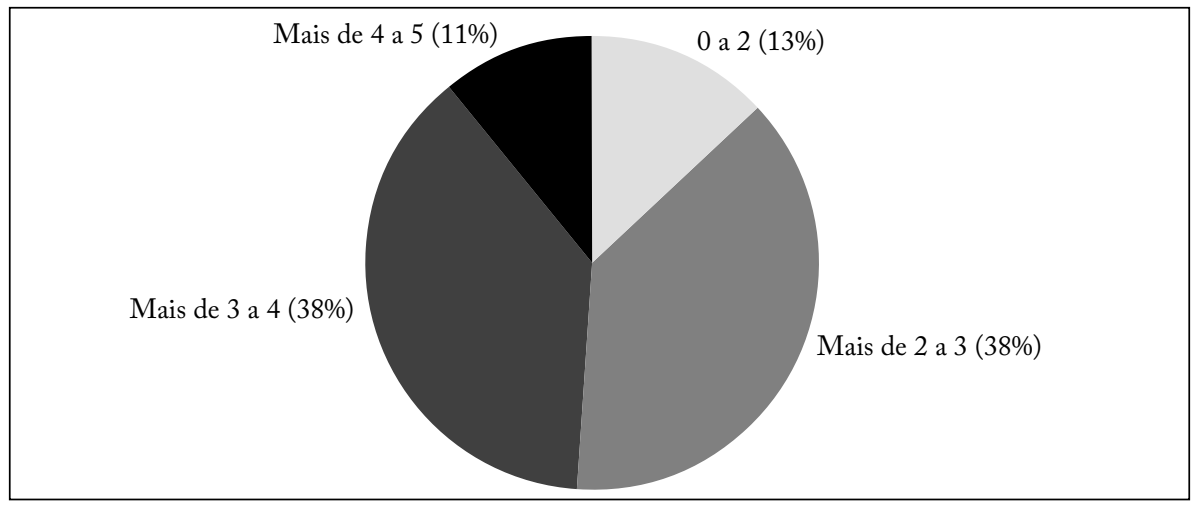

Figura 3 - Distribuição percentual das escolas de educação básica segundo a média ponderada do indicador de regularidade docente - Brasil, 2013.

Fonte: Brasil (2015).

Elaboração dos autores.

Quadro 3 - Variáveis que compõem o indicador de esforço docente e sua categorização.

\begin{tabular}{|l|c|}
\hline Variáveis & \multicolumn{1}{c|}{ Categorização } \\
\hline $\begin{array}{l}\text { Número de } \\
\text { escolas }\end{array}$ & $\begin{array}{c}\text { O número de escolas de atuação é dividido em quatro categorias (uma escola, duas } \\
\text { escolas, três escolas e quatro escolas ou mais). }\end{array}$ \\
\hline $\begin{array}{l}\text { Número de } \\
\text { etapas }\end{array}$ & $\begin{array}{c}\text { São consideradas as seguintes classificações: educação infantil; anos iniciais; anos } \\
\text { finais; ensino médio (incluindo ensino médio integrado); educação profissional; } \\
\text { e Educação de Jovens e Adultos (EJA) (qualquer etapa). A variável final oscila, } \\
\text { portanto, de um a seis, de acordo com o número de etapas nas quais o docente leciona. } \\
\text { Não há distinção entre as modalidades regular e especial na construção dessa variável. }\end{array}$ \\
\hline $\begin{array}{l}\text { Número de } \\
\text { turnos }\end{array}$ & $\begin{array}{c}\text { Para avaliar o número de turnos de trabalho, as turmas de cada docente são } \\
\text { classificadas de acordo com seu horário, de início em matutino (05h00min às } \\
\text { 10h59min), vespertino (11h00min às 16h59min), ou noturno (17h00min às } \\
\text { 23h59min), e, por fim, o docente é classificado conforme o número de turnos em que } \\
\text { suas turmas funcionam. }\end{array}$ \\
\hline $\begin{array}{l}\text { Número de } \\
\text { alunos }\end{array}$ & $\begin{array}{c}\text { A categorização da variável número de alunos atendidos por docente é dividida em } \\
\text { seis categorias (0 a 25; 25 a 50; 50 a 150; 150 a 300; 300 a 400; e acima de 400). } \\
\text { Deve-se ressaltar que tal característica representa a quantidade total de alunos, } \\
\text { independentemente da etapa e disciplina em que o professor atua. Por exemplo, se o } \\
\text { professor leciona para 70 alunos no ensino médio e para 25 na educação profissional, } \\
\text { a variável recebe valor igual a 95. }\end{array}$ \\
\hline
\end{tabular}

Fonte: Brasil (2014b).

Elaboração dos autores. 
A construção dos níveis de esforço agrupa as categorias de percentual mais elevado de cada item. Foram agregadas as categorias contíguas com os percentuais mais altos, até que a soma destes atingisse pelo menos dois terços do total do grupo. O Quadro 4 apresenta a descrição dos níveis com base na distribuição empírica das variáveis.

Tomando como referência esses resultados, pode-se concluir que, quanto maior é o nível em que o docente se enquadra, piores serão suas condições de trabalho e maior será o seu esforço docente. Segundo os dados sumarizados na Figura 4, a distribuição dos docentes que atuam no ensino médio se concentra principalmente no nível 4 (43\%). Esse nível caracteriza-se por docentes que atendem entre 50 e 400 alunos, atuam em dois turnos, em uma ou duas escolas e em duas etapas. As melhores condições de trabalho (nível 1) incluem apenas $1 \%$ dos docentes. Se fosse feita uma análise que agregasse os níveis 1, 2 e 3 em uma categoria e os níveis 4, 5 e 6 em outra, $34 \%$ dos docentes estariam distribuídos na primeira categoria, e $66 \%$,

\section{Quadro 4-Descrição dos níveis de esforço docente.}

\begin{tabular}{|c|c|}
\hline Níveis & Descrição* \\
\hline Nível 1 & Docente que tem até 25 alunos e atua em um único turno, escola e etapa. \\
\hline Nível 2 & Docente que tem entre 25 e 150 alunos e atua em um único turno, escola e etapa. \\
\hline Nível 3 & $\begin{array}{l}\text { Docente que tem entre } 25 \text { e } 300 \text { alunos } \\
\text { e atua em um ou dois turnos em uma única escola e etapa. }\end{array}$ \\
\hline Nível 4 & $\begin{array}{l}\text { Docente que tem entre } 50 \text { e } 400 \text { alunos } \\
\text { e atua em dois turnos, em uma ou duas escolas e em duas etapas. }\end{array}$ \\
\hline Nível 5 & $\begin{array}{l}\text { Docente que tem mais de } 300 \text { alunos } \\
\text { e atua nos três turnos, em duas ou três escolas e em duas ou três etapas. }\end{array}$ \\
\hline Nível 6 & $\begin{array}{l}\text { Docente que tem mais de } 400 \text { alunos } \\
\text { e atua nos três turnos, em duas ou três escolas e em duas ou três etapas. }\end{array}$ \\
\hline
\end{tabular}

*Características apresentadas por pelo menos dois terços dos docentes.

Fonte: Brasil (2014b).

Elaboração dos autores.

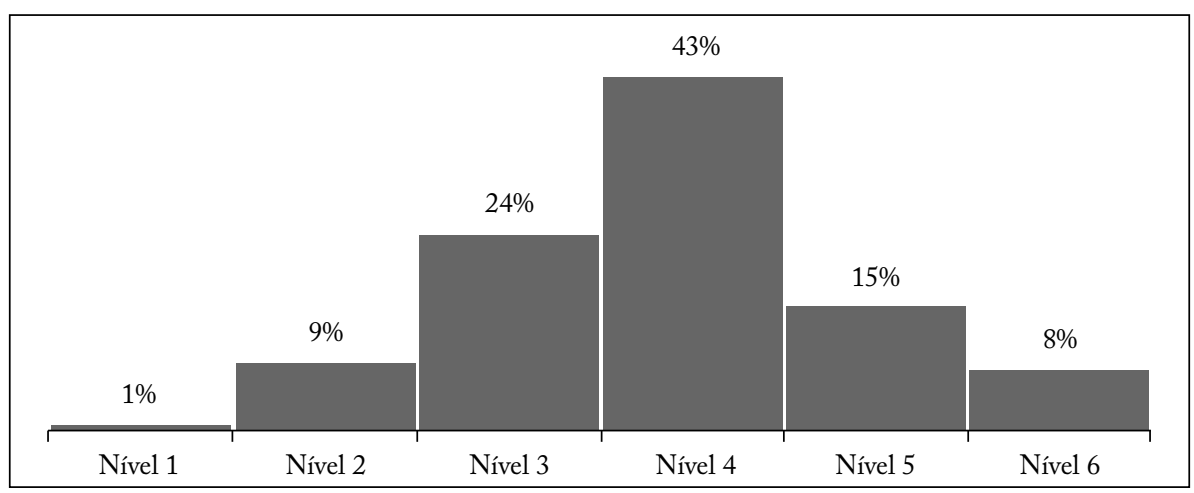

Figura 4-Distribuição dos docentes que atuam no ensino médio de acordo com o nível de esforço docente-Brasil, 2013. Fonte: Brasil (2014b).

Elaboração dos autores. 
na segunda. $\mathrm{O}$ resultado desse indicador é bastante preocupante, pois 1 a cada 100 docentes tem condições relativamente melhores de trabalho nesses moldes.

A nota técnica n. 39/2014 do MEC/INEP descreve que esse indicador sintetiza, em uma única medida, aspectos do trabalho do professor que contribuem para a sobrecarga no exercício da profissão (Brasil, 2014b). O esforço do professor certamente envolve outros fatores e outras dimensões não contempladas neste trabalho. Todavia, os aspectos ora considerados estão presentes no Censo Escolar, o que permite sua medida de forma sólida. Conforme o MEC, o indicador construído em 2014 mostrou-se com grande potencial para contextualização dessa característica do universo docente.

Já o indicador de complexidade de gestão da escola é apresentado pela nota técnica n. 40/2014 do MEC/INEP e visa mensurar o nível de complexidade de gestão das escolas de educação básica brasileiras (Brasil, 2014c). A equipe técnica de construção do indicador assume que a complexidade da gestão escolar se concretiza em quatro características: porte da escola; número de turnos de funcionamento; complexidade das etapas ofertadas pela escola; e número de etapas/modalidades oferecidas. As variáveis criadas para representar essas características são do tipo ordinal, nas quais as categorias mais elevadas indicam maior complexidade de gestão (Quadro 5).

\begin{tabular}{|c|c|}
\hline & $\begin{array}{l}\text { Quadro } 5 \text { - Variáveis que compõem o indicador de } \\
\text { complexidade de gestão da escola e sua categorização. }\end{array}$ \\
\hline Variáveis & Categorização \\
\hline Porte da escola & $\begin{array}{l}\text { O porte da escola é mensurado pelo número de matrículas de escolarização de acordo } \\
\text { com seis categorias (até } 50 \text { matrículas; de } 51 \text { a } 150 \text { matrículas; de } 151 \text { a } 300 \text { matrículas; } \\
\text { de } 301 \text { a } 500 \text { matrículas; de } 501 \text { a } 1.000 \text { matrículas; e mais de } 1.000 \text { matrículas). } \\
\text { Assume-se que escolas que atendem mais alunos são mais complexas. }\end{array}$ \\
\hline $\begin{array}{l}\text { Número de } \\
\text { turnos }\end{array}$ & $\begin{array}{l}\text { Para o cálculo do número de etapas/modalidades ofertadas pela escola, são consideradas } \\
\text { as seguintes classificações: educação infantil regular; anos iniciais regular; anos finais } \\
\text { regular; ensino médio regular; educação profissional regular (incluindo ensino médio } \\
\text { integrado); EJA (qualquer etapa); e educação especial (qualquer etapa). A variável final } \\
\text { varia de um a sete, correspondendo ao número de etapas/modalidades oferecidas pela } \\
\text { escola. Assume-se que escolas que oferecem mais etapas são mais complexas. }\end{array}$ \\
\hline $\begin{array}{l}\text { Complexidade } \\
\text { das etapas }\end{array}$ & $\begin{array}{l}\text { A variável indica qual das etapas ofertadas pela escola atenderia, teoricamente, alunos } \\
\text { com idade mais elevada. Parte-se do pressuposto de que, quanto mais avançadas forem } \\
\text { a idade dos alunos e as etapas oferecidas, maiores serão o número de docentes, de } \\
\text { arranjos para a organização das grades curriculares e de desafios para a manutenção } \\
\text { do aluno na escola. Para isso, as escolas são classificadas nas seguintes categorias: } \\
\text { escolas com oferta de matrículas até a educação infantil ou os anos iniciais do ensino } \\
\text { fundamental; até os anos finais do ensino fundamental; até o ensino médio ou a } \\
\text { educação profissional; com oferta de EJA (independente da etapa). }\end{array}$ \\
\hline $\begin{array}{l}\text { Número de } \\
\text { etapas }\end{array}$ & $\begin{array}{l}\text { Para avaliar o número de turnos de funcionamento das escolas, as turmas de cada } \\
\text { uma delas são classificadas de acordo com seu horário, de início em matutino } \\
\text { (05h00min às } 10 \mathrm{~h} 59 \mathrm{~min}) \text {, vespertino ( } 11 \mathrm{~h} 00 \mathrm{~min} \text { às } 16 \mathrm{~h} 59 \mathrm{~min}) \text { ou noturno } \\
\text { (17h00min às } 23 \mathrm{~h} 59 \mathrm{~min}) \text {, e, por fim, a escola é classificada de acordo com o } \\
\text { número de turnos em que suas turmas funcionam. Assume-se que escolas que } \\
\text { funcionam em mais turnos são mais complexas. }\end{array}$ \\
\hline
\end{tabular}

Fonte: Brasil (2014c).

Elaboração dos autores. 
A descrição da metodologia de construção do indicador, na nota técnica supracitada, revela que, para avaliar o nível de associação entre as variáveis selecionadas, foi estimada a matriz de correlação policórica ${ }^{2}$ e, posteriormente, verificou-se a dimensionalidade dos dados por meio da análise de componentes principais. Esse tipo de análise multivariada é uma técnica estatística que tem por finalidade básica a análise dos dados usados visando a sua redução, à eliminação de sobreposições e à escolha das formas mais representativas de dados a partir de combinações lineares das variáveis originais. Os itens finais, para comporem a complexidade da gestão escolar, são apresentados no Quadro 6.

A nota técnica n. 40/2014 do MEC/INEP revela que o indicador de complexidade de gestão da escola das escolas resume, em uma única medida, as informações sobre porte, turnos de funcionamento, nível de complexidade das etapas e quantidade de etapas ofertadas (Brasil, 2014c). Embora a gestão da escola certamente envolva outros fatores e outras dimensões não contempladas aqui, o indicador apresenta potencial para contextualização dos resultados das avaliações. Tendo isso em vista, o INEP estuda a inclusão de novos quesitos no Censo Escolar, visando ao seu aprimoramento e de outros indicadores que contribuem para a avaliação do contexto da oferta educacional no país.

Observando as Figuras 5 e 6, pode-se perceber que a maior concentração de escolas encontra-se em níveis de complexidade mais baixos (1 e 2) - trata-se de escolas menores, com poucos turnos e poucas etapas (56\%). Já as matrículas se concentram em escolas com níveis de complexidade mais altos (níveis 4, 5 e 6), representando 59\%. Esse fato está associado ao perfil das escolas: escolas menores, com menos complexidade, acolhem menos alunos. Dessa forma, uma maior quantidade de alunos está em escolas com maior complexidade de gestão.

Quadro 6 - Descrição dos níveis de complexidade da gestão escolar.

\begin{tabular}{|c|c|}
\hline Níveis & Descrição* \\
\hline Nível 1 & $\begin{array}{l}\text { Porte inferior a } 50 \text { matrículas, operando em único turno e etapa e apresentando a } \\
\text { educação infantil ou os anos iniciais como etapa mais elevada. }{ }^{* *}\end{array}$ \\
\hline Nível 2 & $\begin{array}{l}\text { Porte entre } 50 \text { e } 300 \text { matrículas, operando em dois turnos, com oferta de até duas etapas, } \\
\text { e apresentando a educação infantil ou os anos iniciais como etapa mais elevada. }\end{array}$ \\
\hline Nível 3 & $\begin{array}{c}\text { Porte entre } 50 \text { e } 500 \text { matrículas, operando em dois turnos, com duas ou três etapas, e } \\
\text { apresentando os anos finais como etapa mais elevada. }\end{array}$ \\
\hline Nível 4 & $\begin{array}{l}\text { Porte entre } 150 \text { e } 1.000 \text { matrículas, operando em dois ou três turnos, com duas ou três } \\
\text { etapas, e apresentando o ensino médio/profissional ou a EJA como etapa mais elevada. }\end{array}$ \\
\hline Nível 5 & $\begin{array}{c}\text { Porte entre } 150 \text { e } 1.000 \text { matrículas, operando em três turnos, com duas ou três etapas, e } \\
\text { apresentando a EJA como etapa mais elevada. }\end{array}$ \\
\hline Nível 6 & $\begin{array}{l}\text { Porte superior a } 500 \text { matrículas, operando em três turnos, com quatro ou mais etapas, e } \\
\text { apresentando a EJA como etapa mais elevada. }\end{array}$ \\
\hline
\end{tabular}

*Características apresentadas por pelo menos dois terços das escolas; **Considerando a idade dos alunos atendidos. Fonte: Brasil (2014c).

Elaboração dos autores.

2 Quando as variáveis são categóricas, não quantitativas. 
$\mathrm{O}$ indicador de nível socioeconômico das escolas foi instituído com base nos dados da Prova Brasil, da Avaliação Nacional da Educação Básica (ANEB) e do Exame Nacional do Ensino Médio (ENEM) de 2011 a 2013 (Brasil, 2014d).

No Quadro 7 constam o intervalo de pontos e a descrição dos níveis da escala de mensuração desse indicador. Os níveis da escala são aplicados aos estudantes para demonstrar o padrão de vida dos alunos.

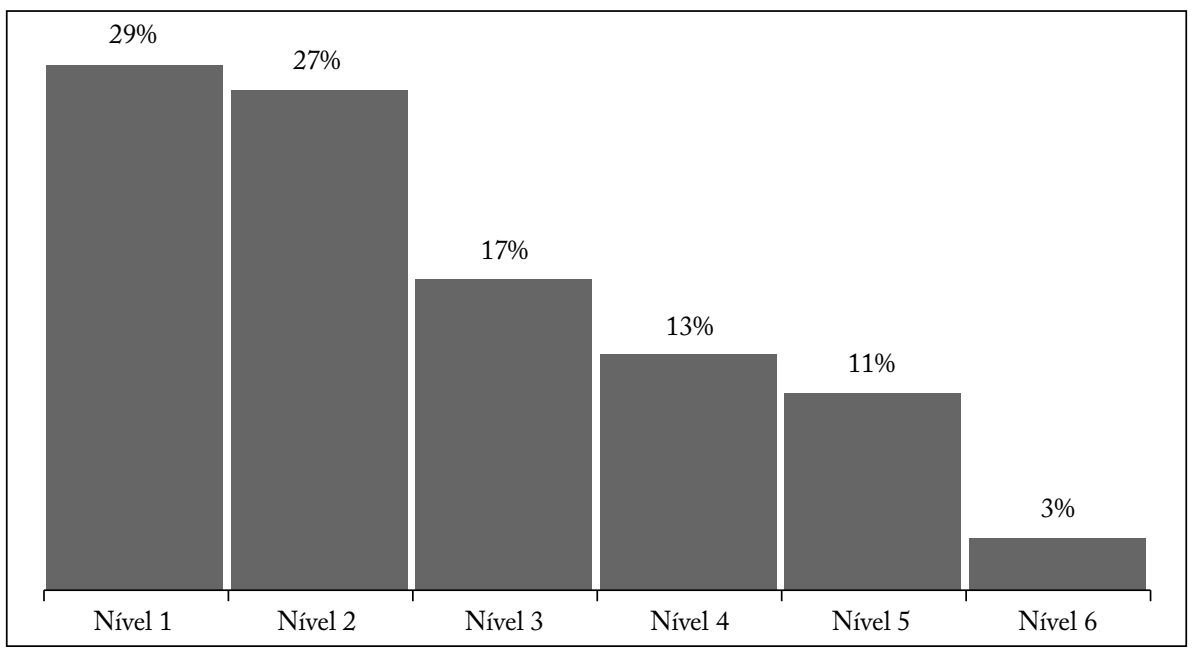

Figura 5 - Percentual de escolas do Censo Escolar da Educação Básica segundo o nível de complexidade de gestão Brasil, 2013.

Fonte: Brasil (2014c).

Elaboração dos autores.

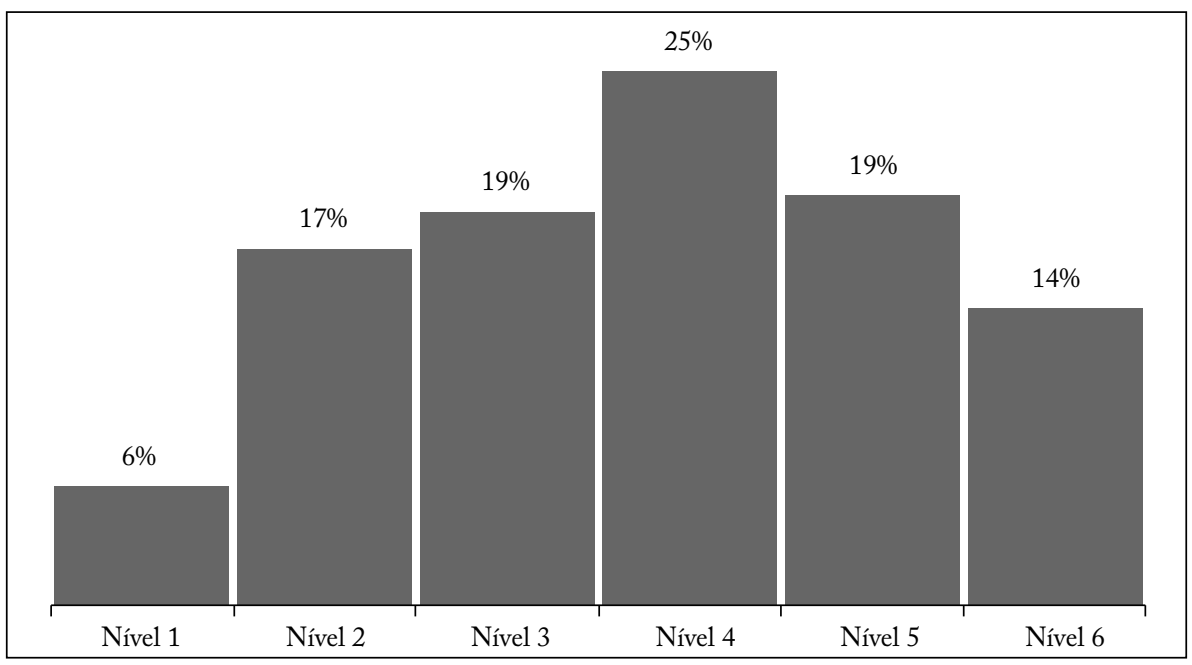

Figura 6 - Percentual de matrículas do Censo Escolar da Educação Básica segundo o nível de complexidade de gestão Brasil, 2013.

Fonte: Brasil (2014c).

Elaboração dos autores. 


\section{Quadro 7 - Descrição dos níveis socioeconômicos dos alunos.}

\begin{tabular}{|c|c|}
\hline Níveis & Descrição \\
\hline Nível 1 & $\begin{array}{l}\text { Até } 30 \\
\text { Este é o menor nível da escala, e os alunos, de modo geral, indicam que há em sua casa bens } \\
\text { elementares, como uma televisão em cores, uma geladeira, um telefone celular, dois quartos e } \\
\text { um banheiro; não contratam empregada mensalista nem diarista; a renda familiar mensal é de } \\
\text { até um salário mínimo; e seus pais ou responsáveis possuem ensino fundamental completo ou } \\
\text { estão cursando esse nível de ensino. }\end{array}$ \\
\hline Nível 2 & $\begin{array}{l}\text { Neste nível, os alunos, de modo geral, indicam que há em sua casa bens elementares, como } \\
\text { uma televisão em cores, um rádio, uma geladeira, um telefone celular, dois quartos e um } \\
\text { banheiro; bens complementares, como videocassete ou DVD; não contratam empregada } \\
\text { mensalista nem diarista; a renda familiar mensal é de até um salário mínimo; e seus pais ou } \\
\text { responsáveis possuem ensino fundamental completo ou estão cursando esse nível de ensino. }\end{array}$ \\
\hline Nível 3 & $\begin{array}{l}41 \text { até } 50 \\
\text { Neste nível, os alunos, de forma geral, indicam que há em sua casa bens elementares, como } \\
\text { uma televisão em cores, um rádio, uma geladeira, um telefone celular, dois quartos e um } \\
\text { banheiro; bens complementares, como videocassete ou DVD, máquina de lavar roupas e } \\
\text { computador; possuem acesso à internet; não contratam empregada mensalista nem diarista; } \\
\text { a renda familiar mensal está entre um e um salário mínimo e meio; e seu pai e sua mãe (ou } \\
\text { responsáveis) possuem ensino fundamental completo ou estão cursando esse nível de ensino. }\end{array}$ \\
\hline Nível 4 & $\begin{array}{l}51 \text { até } 60 \\
\text { Já neste nível os alunos, de modo geral, indicam que há em sua casa bens elementares, como } \\
\text { um rádio, uma geladeira, dois telefones celulares, até dois quartos e um banheiro, duas ou mais } \\
\text { televisões em cores; bens complementares, como videocassete ou DVD, máquina de lavar } \\
\text { roupas, computador; bens suplementares, como freezer, um ou mais telefones fixos e um carro; } \\
\text { possuem acesso à internet; não contratam empregada mensalista nem diarista; a renda familiar } \\
\text { mensal está entre um e meio e cinco salários mínimos; e seu pai e sua mãe (ou responsáveis) } \\
\text { possuem ensino fundamental completo ou estão cursando esse nível de ensino. }\end{array}$ \\
\hline Nível 5 & $\begin{array}{l}\qquad 1 \text { até } 70 \\
\text { Neste nível os alunos, de maneira geral, indicam que há em sua casa uma quantidade maior de bens } \\
\text { elementares, como três quartos e dois banheiros; bens complementares, como videocassete ou DVD, } \\
\text { máquina de lavar roupas, computador; bens suplementares, como freezer, um ou mais telefones fixos, } \\
\text { um carro, além de uma TV por assinatura e um aspirador de pó; possuem acesso à internet; não } \\
\text { contratam empregada mensalista nem diarista; a renda familiar mensal é maior, entre cinco e sete } \\
\text { salários mínimos; e seu pai e sua mãe (ou responsáveis) possuem ensino médio completo. }\end{array}$ \\
\hline Nível 6 & $\begin{array}{l}71 \text { até } 80 \\
\text { Neste nível, os alunos, de forma geral, indicam que há em sua casa uma quantidade maior } \\
\text { de bens elementares, como três quartos e três banheiros; bens complementares, como } \\
\text { videocassete ou DVD, máquina de lavar roupas, computador; bens suplementares, como } \\
\text { freezer, telefones fixos, uma TV por assinatura, um aspirador de pó e dois carros; possuem } \\
\text { acesso à internet; não contratam empregada mensalista nem diarista; a renda familiar } \\
\text { está acima de sete salários mínimos; e seu pai e sua mãe (ou responsáveis) completaram a } \\
\text { faculdade e/ou podem ter concluído ou não um curso de pós-graduação. }\end{array}$ \\
\hline Nível 7 & $\begin{array}{l}\text { Mais de } 80 \\
\text { Este é o maior nível da escala, e os alunos, de maneira geral, indicam que há em sua casa uma } \\
\text { quantidade maior de bens elementares, como duas ou mais geladeiras e três ou mais televisões em } \\
\text { cores, por exemplo; bens complementares, como videocassete ou DVD, máquina de lavar roupas, } \\
\text { computador; maior quantidade de bens suplementares, tal como três ou mais carros e TV por } \\
\text { assinatura; possuem acesso à internet; contratam empregada mensalista ou diarista até duas vezes } \\
\text { por semana; a renda familiar mensal é alta, acima de sete salários mínimos; e seu pai e sua mãe (ou } \\
\text { responsáveis) completaram a faculdade e/ou podem ter concluído ou não um curso de pós-graduação. }\end{array}$ \\
\hline
\end{tabular}

Fonte: Brasil (2014d).

Elaboração dos autores. 
O padrão socioeconômico dos alunos melhora conforme aumenta o nível no qual ele está enquadrado - quanto às escolas, os níveis funcionam da mesma maneira. A nota técnica (Brasil,2014d) descreve também que o nível socioeconômico da escola é definido como a média aritmética simples do nível socioeconômico de seus alunos, no caso de escolas com mais de dez alunos na base de dados.

Utilizando a técnica estatística de análise de Cluster, também designada como análise de agrupamentos, os responsáveis pela constituição desse indicador buscaram agrupar dados por afinidades. Essa é uma técnica de análise multivariada que tem por objetivo agrupar informações por afinidades.

Análise de agrupamentos é o nome para um grupo de técnicas multivariadas cuja finalidade primária é agregar objetos de modo que cada objeto é muito semelhante aos outros no agrupamento em relação a algum critério de seleção predeterminado. (Hair et al., 2005, p. 384)

A aplicação dessa técnica definiu sete cortes/grupos classificados, conforme Figura 7. Considerando os resultados obtidos e agrupando-os por finalidade (intensidade), a escala, com três pontos, fica assim: baixo (21\%), médio (23\%) e alto (56\%). Por essa perspectiva, a maior concentração do público pesquisado enquadra-se nas faixas mais altas do indicador de nível socioeconômico.

Os dados apresentados até aqui revelam aspectos importantes, que podem ajudar a esclarecer a complexidade que cerca a problemática da avaliação. A utilização dos indicadores descritos evidencia, assim, a necessidade de um entendimento efetivo a seu respeito, bem como acerca das relações que podem ser estabelecidas para que se chegue a explicações mais amplas da realidade estudada. Essa perspectiva analítica é apresentada a seguir, ao tratar da realidade das escolas estaduais de ensino médio de Porto Alegre.

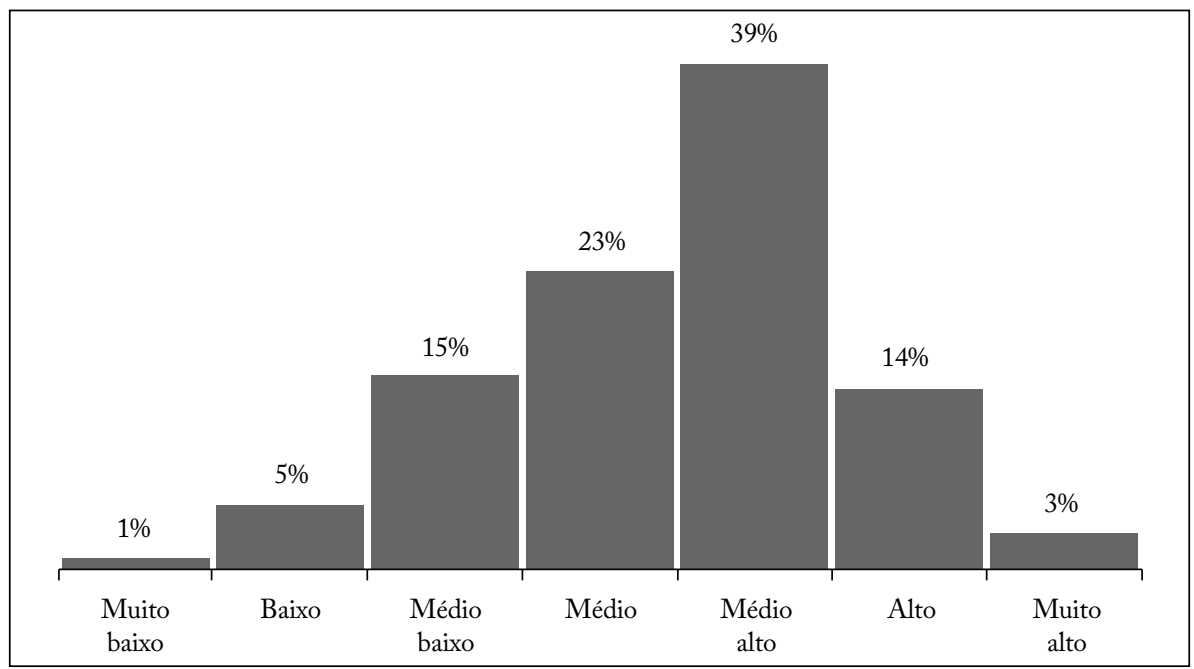

Figura 7-Distribuição de escolas por grupo, de acordo com o indicador de nível socioeconômico, no período de 2011 a 2013. Fonte: Brasil (2014d).

Elaboração dos autores. 


\section{A REALIDADE DE ESCOLAS ESTADUAIS DE ENSINO MÉDIO DE PORTO ALEGRE}

O universo investigado totalizou 69 escolas públicas estaduais, com matrículas no ensino médio, em Porto Alegre, Rio Grande do Sul. Esse total envolveu, em 2015, 37.952 matrículas, das quais 33.356 (87,89\%) eram na modalidade ensino médio, e 4.596 (12,11\%), na modalidade de educação profissional, incluindo escolas técnicas.

As variáveis utilizadas na análise das escolas foram os indicadores de reprovação, abandono e defasagem idade-série, bem como os indicadores recentes apresentados pelo INEP, que podem contribuir para ampliar a visão acerca da realidade escolar de cada unidade pesquisada, avaliando assim o esforço docente, o nível socioeconômico, a complexidade de gestão da escola, a adequação da formação docente e o índice de regularidade do corpo docente.

$\mathrm{Na}$ Tabela 2, são apresentadas as escolas públicas estaduais de Porto Alegre, de acordo com seus resultados em alguns indicadores de processos de avaliação e de desempenho. Os indicadores mais recentes, apresentados pelo INEP, também são considerados na constituição dessa tabela.

Na primeira coluna da Tabela 2, há o código utilizado para cada escola.Já na segunda, consta o percentual de docentes com nível 6 (referente ao indicador que avalia o esforço docente) presentes na escola. Em seguida, é apresentado o porte da escola levando-se em conta o número de alunos, incluindo todos os níveis. Na quarta e quinta colunas, aparecem, respectivamente, os indicadores de nível socioeconômico absoluto e segmentado, caso em que a escola recebe uma pontuação de pelo menos 30 pontos, que vai aumentando à medida que cresce o nível socioeconômico de seus alunos. Em conformidade com essa pontuação, é estabelecida uma escala de pontos que classifica o indicador de nível socioeconômico da escola, que varia de muito baixo até muito alto.

$\mathrm{Na}$ sexta coluna, é possível visualizar o indicador de complexidade de gestão da escola, que é composto de um conjunto de variáveis com diferentes pesos atribuídos conforme a expressividade da informação. $\mathrm{Na}$ sétima coluna, o indicador apresentado é o de adequação da formação docente, que é mensurado em cinco grupos levando em consideração a formação do corpo docente. Foi considerado apenas do percentual dos docentes da escola que compõem o Grupo 5.

$\mathrm{Na}$ oitava coluna, consta o indicador de regularidade do corpo docente, que avalia a permanência dos docentes nas escolas nos últimos cinco anos. "O IRD [indicador de regularidade do corpo docente] atribui uma pontuação do modo que a presença em anos mais recentes seja mais valorizada e a regularidade em anos consecutivos também seja considerada" (Brasil, 2015). Nas três últimas colunas, são apresentados os indicadores de defasagem idade-série, reprovação e abandono, focos principais deste estudo.

Com essa tabela, é possível ter uma visão da escola não apenas por meio de indicadores puramente quantitativos, mas também por um conjunto de outros 
Tabela 2 - Cenário das escolas públicas estaduais com ensino médio em Porto Alegre, destacando alguns indicadores.

\begin{tabular}{|c|c|c|c|c|c|c|c|c|c|c|}
\hline $\begin{array}{l}* \\
\mathscr{w} \\
\mathbb{\sigma} \\
0 \\
\tilde{U} \\
\tilde{~}\end{array}$ & 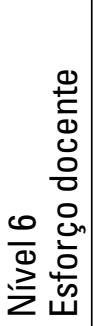 & 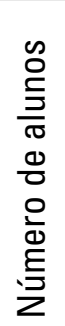 & 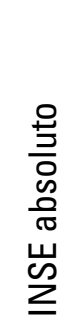 & 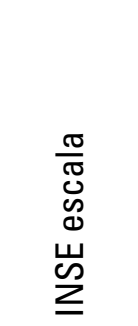 & 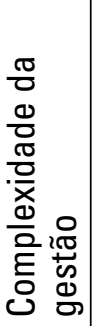 & 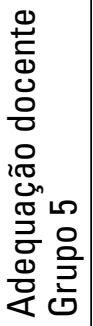 & 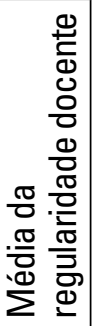 & 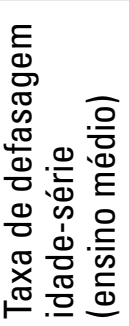 & 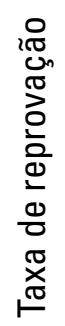 & 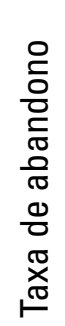 \\
\hline E1 & 11,1 & 294 & 54,88 & Médio alto & 4 & 2,8 & 3,6 & 13,1 & 11,7 & 0,8 \\
\hline $\mathrm{E} 2$ & 4,2 & 185 & 51,32 & Médio alto & 4 & 2,6 & 3,8 & 34,4 & 28,9 & 2,2 \\
\hline E3 & 0,0 & 515 & 52,39 & Médio alto & 4 & 1,7 & 3,4 & 28,3 & 14,7 & 11,1 \\
\hline E4 & 0,0 & 294 & 53,12 & Médio alto & 4 & 0,0 & 3,5 & 34,1 & 20,0 & 2,5 \\
\hline $\mathrm{E} 5$ & 4,3 & 405 & 52,86 & Médio alto & 4 & 4,3 & 3,5 & 32,6 & 26,1 & 2,4 \\
\hline E6 & 4,3 & 216 & 52,43 & Médio alto & 4 & 1,9 & 3,3 & 49,6 & 20,1 & 22,5 \\
\hline E7 & 6,7 & 561 & 51,28 & Médio alto & 4 & 4,3 & 3,8 & 47,8 & 26,0 & 12,3 \\
\hline $\mathrm{E} 8$ & 0,0 & 531 & 56,39 & Alto & 4 & 0,8 & 3,9 & 20,2 & 13,9 & 7,4 \\
\hline E9 & 8,7 & 225 & 52,40 & Médio alto & 6 & 1,2 & 3,4 & 59,9 & 38,0 & 13,7 \\
\hline E10 & 5,9 & 278 & 50,79 & Médio alto & 4 & 0,0 & 4,0 & 44,5 & 24,6 & 3,1 \\
\hline E11 & 7,8 & 454 & 54,89 & Médio alto & 5 & 0,0 & 3,8 & 42,5 & 16,7 & 7,3 \\
\hline E12 & 0,0 & 385 & 53,84 & Médio alto & 4 & 0,0 & 4,0 & 17,2 & 11,2 & 10,6 \\
\hline E13 & 0,0 & 141 & 53,18 & Médio alto & 4 & 7,7 & 3,8 & 36,1 & 23,2 & 11,1 \\
\hline E14 & 18,5 & 206 & 53,36 & Médio alto & 6 & 0,0 & 3,5 & 22,4 & 16,8 & 12,9 \\
\hline E15 & 6,9 & 379 & 54,93 & Médio alto & 4 & 5,3 & 3,5 & 33,9 & 23,6 & 10,7 \\
\hline E16 & 8,7 & 370 & 52,57 & Médio alto & 5 & 0,0 & 3,9 & 46,3 & 10,7 & 21,4 \\
\hline E17 & 12,5 & 225 & 54,26 & Médio alto & 5 & 0,0 & 4,0 & 49,5 & 21,8 & 6,9 \\
\hline E18 & 0,0 & 271 & 56,75 & Alto & 5 & 2,2 & 3,2 & 44,7 & 10,6 & 7,3 \\
\hline E19 & 0,0 & 283 & 51,40 & Médio alto & 6 & 17,3 & 4,0 & 32,4 & 4,3 & 19,4 \\
\hline E20 & 0,0 & 107 & 55,68 & Alto & 4 & 0,0 & 2,9 & 49,7 & 42,0 & 9,6 \\
\hline $\mathrm{E} 21$ & 8,3 & 316 & 54,45 & Médio alto & 6 & 3,6 & 3,2 & 34,5 & 12,9 & 8,1 \\
\hline $\mathrm{E} 22$ & 6,1 & 214 & 51,66 & Médio alto & 5 & 13,3 & 3,7 & 55,8 & 43,8 & 6,7 \\
\hline E23 & 4,3 & 255 & 52,56 & Médio alto & 4 & 14,7 & 3,7 & 58,8 & 14,0 & 26,7 \\
\hline E24 & 0,0 & 141 & 52,01 & Médio alto & 6 & 8,4 & 3,1 & 63,4 & 7,3 & $2, .9$ \\
\hline E25 & 11,8 & 188 & 53,01 & Médio alto & 4 & 0,0 & 3,3 & 56,8 & 8,6 & 30,9 \\
\hline E26 & 8,3 & 254 & 53,05 & Médio alto & 6 & 9,0 & 3,5 & 50,9 & 19,6 & 29,5 \\
\hline $\mathrm{E} 27$ & 4,2 & 217 & 57,12 & Alto & 6 & 11,9 & 3,5 & 39,1 & 35,2 & 20,0 \\
\hline E28 & 7,7 & 275 & 58,08 & Alto & 5 & 7,2 & 3,8 & 28,2 & 20,8 & 0,5 \\
\hline E29 & 10,0 & 323 & 55,85 & Alto & 5 & 0,0 & 3,9 & 36,7 & 7,9 & 17,8 \\
\hline E30 & 2,9 & 286 & 56,51 & Alto & 5 & 0,0 & 3,2 & 8,4 & 13,9 & 1,1 \\
\hline E31 & 5,9 & 315 & 51,71 & Médio alto & 5 & 0,0 & 3,7 & 63,9 & 42,9 &, .3 \\
\hline E32 & 6,1 & 282 & 54,12 & Médio alto & 5 & 4,0 & 3,2 & 54,0 & 32,9 & 15,0 \\
\hline E33 & 4,5 & 206 & 56,81 & Alto & 4 & 0,0 & 3,7 & 29,7 & 24,1 & 0,6 \\
\hline E34 & 8,3 & 412 & 54,40 & Médio alto & 5 & 5,8 & 3,4 & 49,6 & 29,3 & 15,9 \\
\hline E35 & 12,5 & 202 & 54,86 & Médio alto & 5 & 0,0 & 3,7 & 43,3 & 16,6 & 12,5 \\
\hline
\end{tabular}


Tabela 2 - Continuação.

\begin{tabular}{|c|c|c|c|c|c|c|c|c|c|c|}
\hline 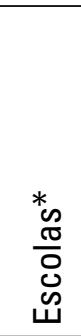 & 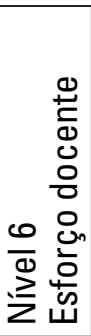 & 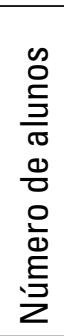 & 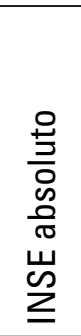 & 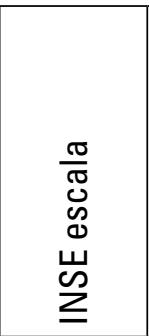 & 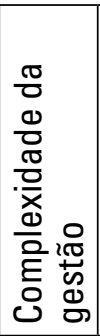 & 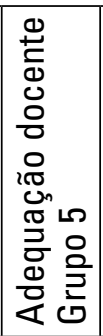 & 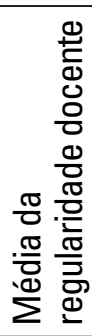 & 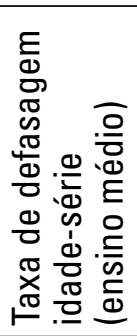 & 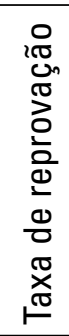 & 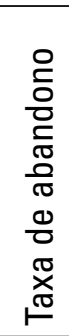 \\
\hline E36 & 8,8 & 180 & 53,71 & Médio alto & 4 & 5,1 & 3,1 & 39,8 & 16,2 & 9,4 \\
\hline E37 & 16,1 & 215 & 52,67 & Médio alto & 6 & 10,0 & 4,0 & 51,7 & 49,7 & 0,2 \\
\hline E38 & 11,8 & 307 & 52,49 & Médio alto & 6 & 0,0 & 3,7 & 36,0 & 19,0 & 7.1 , \\
\hline E39 & 0,0 & 134 & 56,59 & Alto & 6 & 2,9 & 3,3 & 42,5 & 10,6 & 15,3 \\
\hline $\mathrm{E} 40$ & 0,0 & 666 & 56,18 & Alto & 5 & 0,5 & 3,5 & 50,5 & 11,3 & 13,7 \\
\hline E41 & 3,7 & 340 & 55,36 & Alto & 5 & 0,0 & 4,0 & 44,3 & 20,4 & 9,5 \\
\hline E42 & 0,0 & 185 & 55,56 & Alto & 5 & 3,8 & 2,9 & 30,4 & 27,3 & 2,7 \\
\hline E43 & 4,6 & 379 & 50,70 & Médio alto & 4 & 7,4 & 3,6 & 34,4 & 12,2 & 19,6 \\
\hline E44 & 13,0 & 175 & 53,69 & Médio alto & 4 & 5,5 & 3,5 & 43,7 & 13,0 & 16,1 \\
\hline E45 & 5,4 & 466 & 56,69 & Alto & 4 & 7,6 & 3,8 & 25,3 & 11,8 & 8,1 \\
\hline E46 & 3,0 & 170 & 52,71 & Médio alto & 5 & 3,2 & 3,9 & 44,8 & 19,2 & 13,6 \\
\hline E47 & 4,5 & 295 & 54,37 & Médio alto & 5 & 6,1 & 3,6 & 48,7 & 17,6 & 17,8 \\
\hline E48 & 6,9 & 108 & 53,15 & Médio alto & 4 & 13,6 & 3,7 & 38,8 & 13,9 & 5,5 \\
\hline E49 & 7,1 & 349 & 56,01 & Alto & 4 & 3,2 & 3,4 & 40,9 & 21,7 & 1,5 \\
\hline E50 & 5,4 & 346 & 55,40 & Alto & 4 & 4,2 & 4,1 & 50,8 & 34,0 & 1,9 \\
\hline E51 & 5,0 & 395 & 54,80 & Médio alto & 5 & 12,4 & 3,7 & 45,4 & 14,4 & 12,9 \\
\hline E52 & 10,5 & 263 & 61,07 & Alto & 4 & 9,0 & 3,4 & 6,3 & 8,9 & 0,0 \\
\hline E53 & 2,3 & 463 & 58,35 & Alto & 5 & 0,0 & 3,8 & 21,3 & 13,7 & 4,1 \\
\hline E54 & 9,1 & 239 & 53,81 & Médio alto & 4 & 8,3 & 3,3 & 51,1 & 13,7 & 27,3 \\
\hline E55 & 8,3 & 273 & 56,40 & Alto & 4 & 0,0 & 4,0 & 51,1 & 31,2 & 22,7 \\
\hline E56 & 2,3 & 323 & 53,82 & Médio alto & 4 & 0,0 & 3,5 & 36,1 & 21,4 & 6,1 \\
\hline E57 & 11,9 & 582 & 53,57 & Médio alto & 5 & 4,3 & 4,0 & 61,4 & 19,1 & 19,6 \\
\hline E58 & 6,7 & 131 & 55,41 & Alto & 4 & 9,7 & 3,1 & 50,0 & 16,7 & 14,3 \\
\hline E59 & 0,0 & 297 & 52,58 & Médio alto & 4 & 0,0 & 3,8 & 46,6 & 11,8 & 15,1 \\
\hline E60 & 0,0 & 206 & 53,71 & Médio alto & 5 & 7,5 & 4,0 & 56,8 & 29,7 & 22,8 \\
\hline E61 & 8,3 & 286 & 54,37 & Médio alto & 6 & 0,0 & 3,8 & 33,5 & 14,2 & 5,8 \\
\hline E62 & 10,0 & 43 & 44,93 & Médio & 6 & 3,1 & 3,4 & 51,4 & 2,9 & 22,1 \\
\hline E63 & 0,0 & 84 & 51,16 & Médio alto & 4 & 20,5 & 3,3 & 66,3 & 9,2 & 32,9 \\
\hline E64 & 0,0 & 382 & 56,79 & Alto & 6 & 0,0 & 3,3 & 26,6 & 4,3 & 5,6 \\
\hline E65 & 4,5 & 119 & 55,68 & Alto & 4 & 17,6 & 3,5 & 38,2 & 19,5 & 13,3 \\
\hline E66 & 2,8 & 335 & 55,21 & Alto & 5 & 18,6 & 3,3 & 66,2 & 20,1 & 38,8 \\
\hline E67 & 0,0 & 148 & 49,08 & Médio & 4 & 6,3 & 3,3 & 55,1 & 13,6 & 30,2 \\
\hline E68 & 8,1 & 161 & 50,95 & Médio alto & 4 & 4,9 & 3,9 & 47,4 & 30,9 & 21,5 \\
\hline E69 & 6,3 & 247 & 54,01 & Médio alto & 4 & 0,0 & 3,7 & 44,6 & 18,8 & 17,7 \\
\hline
\end{tabular}

INSE: indicador de nível socioeconômico; *As escolas não são identificadas.

Fonte: Brasil (2014d). 
indicadores que avaliam aspectos mais qualitativos e revelam particularidades de cada unidade escolar.

Observando os dados da tabela, foram identificados alguns resultados interessantes. Ao realizar uma análise estatística de regressão entre as variáveis apresentadas na tabela e associar a taxa de reprovação e a equação de regressão utilizando o método step wise, ${ }^{3}$ obteve-se o resultado apresentado na Equação 2.

\section{EQUAÇÃO 2 - EQUAÇÃO DE REGRESSÃO DA TAXA DE REPROVAÇÃO EM FUNÇÃO DAS DEMAIS TAXAS}

$\mathrm{TR}=(0,529 \mathrm{x}$ TDIS $)-(0,723 \times \mathrm{TA})+(0,179 \times \mathrm{IED})+5,607$

Onde:

TR = Taxa de reprovação;

TDIS = Taxa de defasagem idade-série;

$\mathrm{TA}=$ Taxa de abandono; e

IED = Esforço docente (com o percentual presente no mais alto nível -6).

As três variáveis que explicam a taxa de reprovação são a taxa de defasagem idade-série, a taxa de abandono e o indicador de esforço docente. Juntas essas variáveis explicam 37,9\% das variações na taxa de reprovação, obtendo uma correlação de 0,62. Os resultados desses indicadores apontam que existe uma tendência, não determinística, de que altas taxas de defasagem idade-série ocasionem alta taxa de reprovação. Como o sinal da taxa de abandono na Equação 2 é negativo, quanto maior tende a ser a taxa de abandono, menor tende a ser a taxa de reprovação. Isso se deve ao fato de que grande parte dos alunos em situação de abandono está nessa condição, pois provavelmente seria reprovada - assim, muito abandono acaba gerando menos reprovação, fato que já havia sido reportado em estudos anteriores referentes ao ensino médio de escolas em São Leopoldo, Rio Grande do Sul (Fritsch, Rocha e Vitelli, 2014a, 2014b).

$\mathrm{O}$ indicador de esforço docente apresenta uma série de níveis que vão desde o mais baixo (nível 1) até o mais alto (nível 6). A variável considerada nessa regressão representa o percentual de docentes no nível 6 - constituído do percentual de professores que têm mais de 400 alunos e atuam em três turnos, duas ou três escolas e em duas ou três etapas do ensino. De forma resumida, as variáveis mais intervenientes no resultado das reprovações em escolas públicas estaduais de Porto Alegre, no ensino médio, são apresentadas na Figura 8.

3 O método step wise, ou método passo a passo, caracteriza-se por ser um procedimento de obtenção da equação de regressão em que as variáveis são colocadas e retiradas do modelo até que se encontre uma combinação ótima de resultados. Com isso, a equação final é a melhor proposta de combinações de variáveis para explicar o resultado da variável resposta (no caso, a taxa de reprovação). 
Nos mesmos moldes da taxa de reprovação, foi feita uma análise utilizando-se a taxa de abandono escolar, que resultou no modelo de regressão final apresentado pela Equação 3.

\section{EQUAÇÃO 3 - EQUAÇÃO DE REGRESSÃO DA TAXA DE ABANDONO EM FUNÇÃO DAS DEMAIS TAXAS}

$\mathrm{TA}=(0,448 \times \mathrm{TDIS})-(0,393 \times \mathrm{TR})+(0,343 \times \mathrm{ACD})-(0,252 \times \mathrm{INSE})+13,685$

Onde:

TA = Taxa de abandono;

TDIS = Taxa de defasagem idade-série;

TR = Taxa de reprovação;

$\mathrm{ACD}=$ Adequação do corpo docente (no grupo 5); e

INSE = Indicador de nível socioeconômico (valor absoluto).

As quatro variáveis que elucidam a taxa de abandono são a taxa de defasagem idade-série, de reprovação, de adequação do corpo docente e de nível socioeconômico. Juntas essas variáveis explicam $60,5 \%$ das variações na taxa de abandono, obtendo uma correlação de 0,78 . Os resultados desses indicadores apontam, também, que altas taxas de defasagem idade-série e adequação do corpo docente ocasionam uma alta taxa de reprovação. Como o sinal das taxas de reprovação e de nível socioeconômico na Equação 3 é negativo, conclui-se que, quanto maior tende a ser a taxa de reprovação e de nível socioeconômico, menor tende a ser a taxa de abandono - a relação entre a taxa de abandono e de reprovação já havia sido discutida anteriormente. Quanto ao indicador de nível socioeconômico, a relação indireta acontece pelo fato de que, quanto maior tende a ser o resultado desse nível, menor tende a ser a taxa de abandono escolar. De forma resumida, tal levantamento é apresentado na Figura 9.

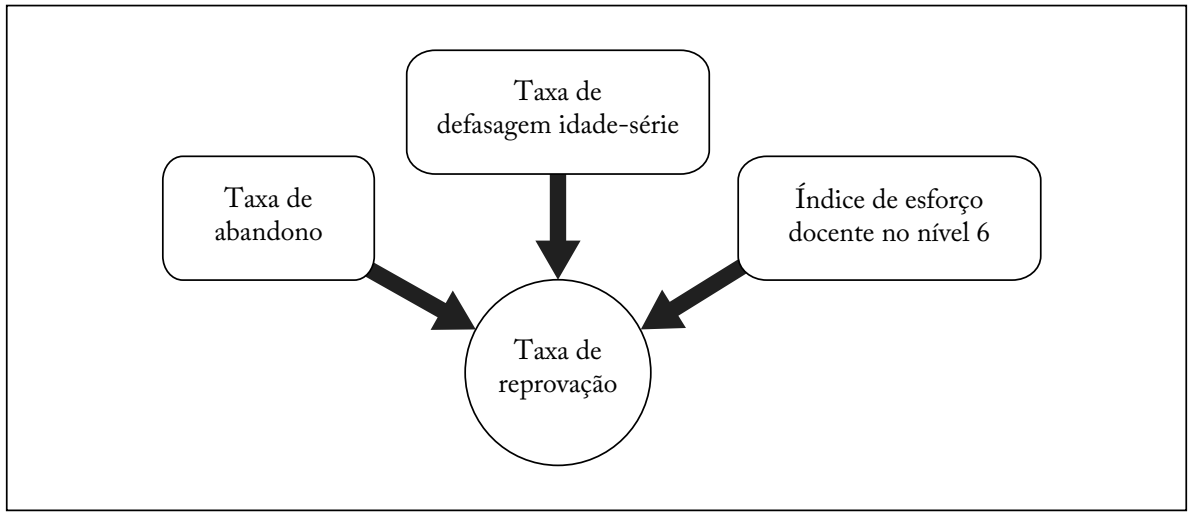

Figura 8 - Apresentação resumida da equação de regressão da taxa de reprovação.

Fonte: Baseada em Brasil (2014d).

Elaboração dos autores. 
Ao associar o resultado da taxa de reprovação e da taxa de abandono escolar no ensino médio das escolas estaduais de Porto Alegre, identificou-se que a taxa de defasagem idade-série é o único indicador que aparece como interveniente nas duas taxas anteriores. Esse fenômeno corrobora os resultados de estudos anteriores com escolas da mesma natureza em outro município gaúcho, São Leopoldo (Fritsch, Rocha e Vitelli, 2014a). Na Figura 10, é possível identificar, por meio da linha de tendência, uma associação entre a taxa de defasagem idade-série e a taxa de reprovação. Apesar de não ser determinística, essa relação demonstra que, quanto maior tende a ser a taxa de defasagem idade-série, maior tende a ser a taxa de reprovação nessa etapa do processo educacional.

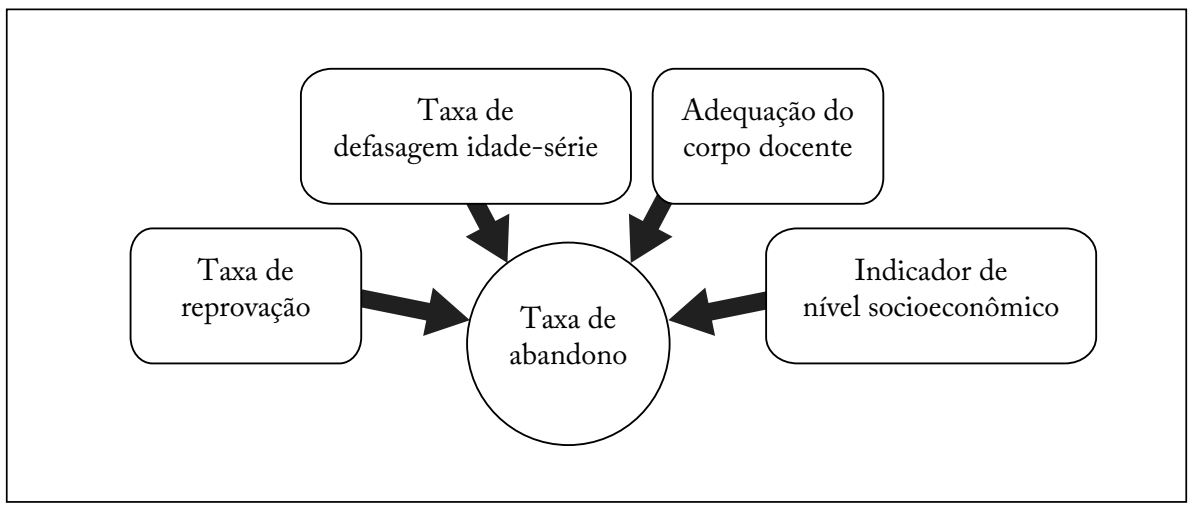

Figura 9 - Apresentação resumida da equação de regressão da taxa de abandono.

Fonte: Baseada em Brasil (2014d).

Elaboração dos autores.

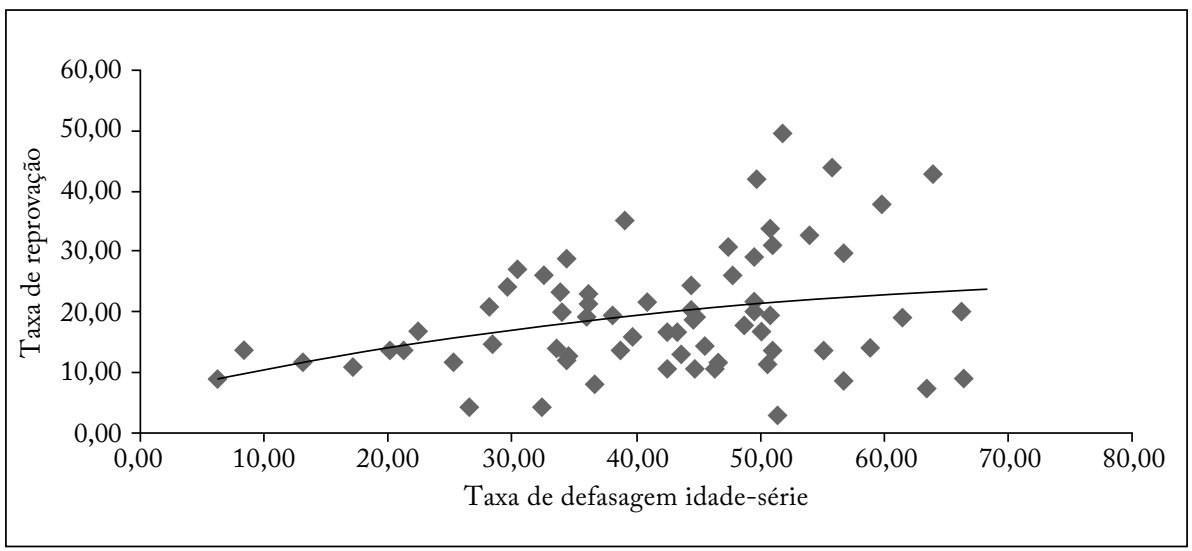

Figura 10 - Dispersão entre a taxa de defasagem idade-série e a taxa de reprovação no ensino médio das escolas estaduais de Porto Alegre.

Fonte: Baseada em Brasil (2014d).

Elaboração dos autores. 
Da mesma forma, a Figura 11 mostra que existe uma relação entre a taxa de defasagem idade-série e a taxa de abandono escolar. Entretanto, tal relação é mais intensificada que a relação entre a taxa de defasagem idade-série e a taxa de reprovação. Isso se deve ao fato de que, como pode ser percebido na Figura 10, a linha de tendência tende a uma estabilidade a partir de uma elevação da taxa de defasagem, sinalizando que esse indicador, quando é muito alto (acima de $50 \%$, aproximadamente), ${ }^{4}$ tem sua influência estabilizada sobre o resultado da taxa de reprovação.

Com relação à taxa de abandono, a linha de tendência tende a ser mais próxima de uma relação exponencial, isto é, os incrementos na taxa de defasagem idade-série tendem a aumentar consideravelmente a taxa de abandono escolar. Dessa forma, a taxa de defasagem idade-série passa a ser um indicador importante a ser observado quando se analisam dados de fluxo escolar.

Esses elementos evidenciam a complexidade existente entre as relações que servem como fatores intervenientes nos resultados dos indicadores educacionais. Em muitos casos, as condições menos desfavoráveis mensuradas por algum indicador não se configuram como determinísticas no resultado de outros, demonstrando que existem aspectos qualitativos ocultos por trás de seus resultados quantitativos. Tais aspectos assinalados são resumidos e apresentados na Figura 12, na qual se estabelecem todas as inter-relações existentes entre as taxas de fluxo escolar com os indicadores de esforço docente, nível socioeconômico e na adequação do corpo docente. Os indicadores de complexidade de gestão da escola e de regularidade do corpo docente não se mostraram significativos na composição dos modelos de regressão. A ausência desses últimos ocorreu em uma realidade específica.

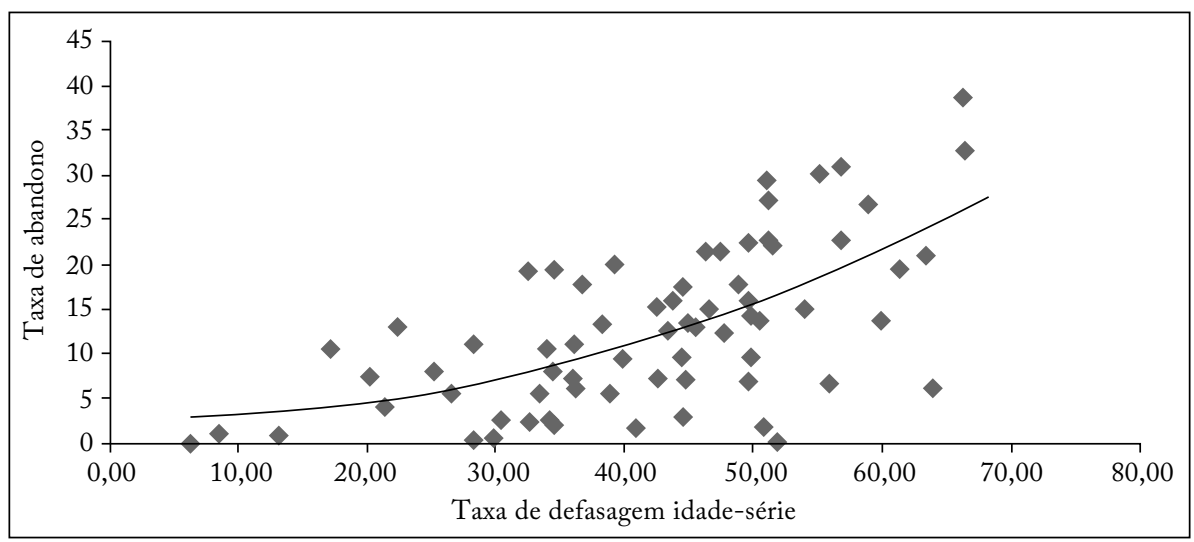

Figura 11 - Dispersão entre a taxa de defasagem idade-série e a taxa de abandono no ensino médio das escolas estaduais de Porto Alegre.

Fonte: Baseada em Brasil (2014d).

Elaboração dos autores.

4 Ponto de inflexão da curva de tendência dos dados (49,60\%). 


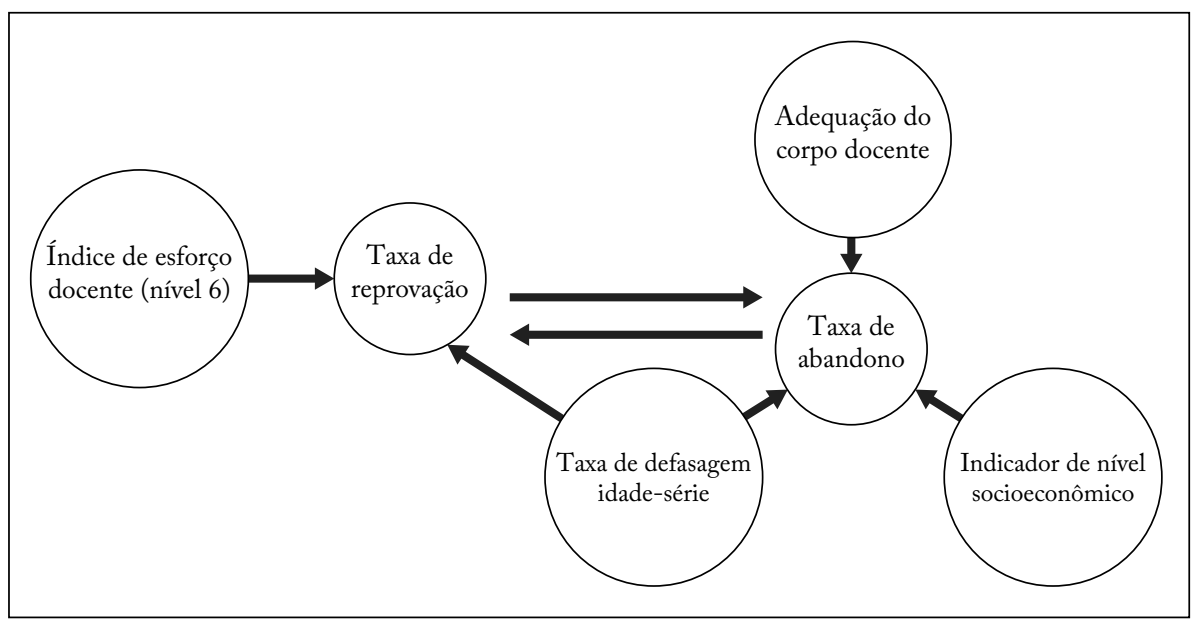

Figura 12 - Inter-relações entre os resultados dos indicadores educacionais presentes no estudo.

Fonte: Baseada em Brasil (2014d).

Elaboração dos autores.

\section{CONSIDERAÇÕES FINAIS}

Merece destaque o fato de que a proposição de uma avaliação de qualidade da escola não pode ser restrita apenas a resultados de indicadores quantitativos. É preciso estabelecer um conjunto mais amplo que considere também aspectos qualitativos da realidade escolar. Nas análises realizadas no estudo foi possível perceber essa necessidade. Além disso, é importante considerar também as correlações decorrentes dos fatores intervenientes entre os indicadores. Dessa forma se amplia o espectro de avaliação para uma dimensão diagnóstica das realidades escolares.

Os resultados apresentados ao longo deste estudo permitem a elaboração de argumentos críticos que sustentam as premissas apresentadas na introdução. Do ponto de vista das políticas públicas, os indicadores, combinados com outros recursos metodológicos de análise de contexto, podem ser instrumentos que permitem identificar e medir aspectos relacionados a determinado conceito, fenômeno, problema ou resultado de uma intervenção na realidade. Nesse sentido, a positividade ocorre pela intencionalidade diagnóstica e pela ocupação de uma função-meio em detrimento de uma intencionalidade de controle/ regulação e de uma função-fim. No entanto, nessa condição, são necessários um conceito claro e transparente e uma metodologia coerente com o que se quer efetivamente avaliar.

A polissemia do conceito de qualidade possibilita sua utilização valendo-se de diferentes significados, de modo que o que dará sentido a esse uso é o conjunto de pressupostos que estruturam as diferentes práticas educacionais no terreno da avaliação. Se os resultados de indicadores educacionais forem empregados como a absoluta expressão da qualidade da educação, é possível que se cheguem a conclusões bastante reducionistas, o que, por si só, limitaria a compreensão mais plena da realidade escolar, em qualquer nível em que seja aplicado. Diante de tal conclusão, este texto procura contribuir para evitar entendimentos simplificados de um processo complexo de avaliação que é muito importante para a educação em nosso país. 


\section{REFERÊNCIAS}

BALl, S. J. Educação global S.A.: novas redes políticas e o imaginário neoliberal. Ponta Grossa: UEPG, 2014.

Bonamino, A. Tempos de avaliação educacional. Rio de Janeiro: Quartet, 2002.

Brasil. Lei n. 9.394, de 20 de dezembro de 1996. Estabelece as Diretrizes e Bases da Educação Nacional. Diário Oficial da União, Brasília, DF, 23 dez. 1996. Disponível em: <http://www.planalto.gov.br/ccivil_03/leis/L9394.htm>. Acesso em: 15 out. 2011.

. Ministério da Educação. Instituto Nacional de Estudos e Pesquisas Educacionais Anísio Teixeira - INEP. Dicionário de indicadores educacionais: fórmulas de cálculo. Coordenação-Geral de Sistemas Integrados de Informações Educacionais. Brasília, DF: INEP, 2004. Disponível em: <http://portal.inep.gov.br/informacao-da-publicacao/-/ asset_publisher/6JYIsGMAMkW1/document/id/486420 >. Acesso em: 12 jun. 2015.

Ministério da Educação. Instituto Nacional de Estudos e Pesquisas Educacionais Anísio Teixeira - INEP. Nota técnica CGCQTI/DEED/INEP n. 11/2015, de 25 de junho de 2015. Brasília, DF: INEP,2015. Disponível em: <http://download.inep. gov.br/informacoes_estatisticas/indicadores_educacionais/2014/docente_regularidade_ vinculo/nota_tecnica_indicador_regularidade_2015.pdf>. Acesso em: 19 set. 2016.

. Ministério da Educação. Instituto Nacional de Estudos e Pesquisas Educacionais Anísio Teixeira - INEP. Nota técnica n. 20/2014, de 21 de novembro de 2014. Brasília, DF: INEP, 2014a. Disponível em: <http://download.inep.gov.br/educacao_basica/ enem/enem_por_escola/2014/nota_tecnica_indicador_adequa\%C3\%A7\%C3\%A3o_ formacao_docente.pdf>.Acesso em: 19 set. 2016.

. Ministério da Educação. Instituto Nacional de Estudos e Pesquisas Educacionais Anísio Teixeira - INEP. Nota técnica n. 39/2014, de 17 de dezembro de 2014. Brasília, DF: INEP, 2014b. Disponível em: <http://download.inep.gov.br/informacoes_estatisticas/ indicadores_educacionais/2014/docente_esforco/nota_tecnica_indicador_docente_ esforco.pdf>. Acesso em: 19 set. 2016.

. Ministério da Educação. Instituto Nacional de Estudos e Pesquisas Educacionais Anísio Teixeira - INEP. Nota técnica n. 40/2014, de 17 de dezembro de 2014. Brasília, DF: INEP, 2014c. Disponível em: <http://download.inep.gov.br/ informacoes_estatisticas/indicadores_educacionais/2014/escola_complexidade_ gestao/nota_tecnica_indicador_escola_complexidade_gestao.pdf $>$. Acesso em: 19 set. 2016.

. Ministério da Educação. Instituto Nacional de Estudos e Pesquisas Educacionais Anísio Teixeira - INEP. Nota técnica indicador de nível socioeconômico das escolas. Brasília, DF: INEP, 2014d. Disponível em: <http://download.inep.gov. br/informacoes_estatisticas/indicadores_educacionais/2014/escola_complexidade_ gestao/nota_tecnica_indicador_escola_complexidade_gestao.pdf $>$. Acesso em: 19 set. 2016.

. Portaria n. 369, de 5 de maio de 2016. Institui o Sistema Nacional de Avaliação da Educação Básica (SINAEB) Nacional. Diário Oficial da União, Brasília, DF, maio 2016. Seção 1, n. 86. 
Brasil. Ministério da Educação. Gabinete do Ministro. Portaria n. 981, de 25 de agosto de 2016. Revoga a Portaria MEC n. 369, de 5 de maio de 2016, e dá outras providências. Diário Oficial da União, Brasília, DF, agosto 201. Seção 1, n. 165, p. 16.

Freitas,D.N.T. A avaliação da educação básica no Brasil.Campinas: Autores Associados, 2007. Fritsch, R.; Rocha, C. S.; VItelli, R. F. Defasagem idade-série em escolas estaduais de ensino médio do Rio Grande do Sul. Revista Brasileira de Estudos Pedagógicos, Brasília: INEP, v. 95, n. 239, p. 218-236, jan./abr. 2014a.

.Para que jovens? Que políticas? Perfil de alunos ingressantes no ensino médio e políticas públicas. In: Dore, R.; Araujo, A. C.; Mendes, J. S. (Orgs.). Evasão na educação: estudos. Brasília: Editora do IFB/RIMEPES, 2014b. p. 131-164.

Hair, J. et al. Análise multivariada de dados. 5. ed. Porto Alegre: Bookman, 2005.

Jannuzzi, P. M. Considerações sobre o uso, mau uso e abuso dos indicadores sociais na formulação e avaliação de políticas públicas municipais. Revista de Administração Pública, Rio de Janeiro: FGV, v. 36, n. 1, p. 51-72, jan./fev. 2002.

. Indicadores sociais no Brasil: conceitos, fontes de dados e aplicações. 4. ed. Campinas: Editora Alínea, 2009.

Silva, M. A.; Cunha, C. Educação básica: políticas, avanços e pendências. Campinas: Autores Associados, 2014.

Souza, D. B.; Duarte, M. R. T.; Oliveira, R. F. (Orgs.). Sistemas educacionais: concepções, tensões e desafios. São Paulo: Edições Loyola, 2015.

Werle, F. O. C. (Org.). Avaliação em larga escala: questões polêmicas. Brasília, DF: Liber Livro, 2012.

\section{SOBRE OS AUTORES}

Ricardo Ferreira Vitelli é doutor em educação pela Universidade do Vale do Rio dos Sinos (UNISINOS). Professor da mesma instituição.

E-mail: vitelli@unisinos.br

Rosangela Fritsch é doutora em educação pela Universidade do Vale do Rio dos Sinos (UNISINOS). Professora da mesma instituição.

E-mail: rosangelaf@unisinos.br

Berenice Corsetti é doutora em educação pela Universidade Estadual de Campinas (UNICAMP). Professora da Universidade do Vale do Rio dos Sinos (UNISINOS).

E-mail: bcorsetti@unisinos.br

Recebido em 22 de setembro de 2016 Aprovado em 3 de julho de 2017 